\title{
Design and Implementation of Intermediate Frequency Dual Band 2-Way Wilkinson Power Divider for Radar System
}

\author{
Taufiqqurrachman and Mashury Wahab \\ Research Center for Electronics and Telecommunications \\ Indonesian Institute of Sciences (PPET - LIPI) \\ LIPI Campus, Sangkuriang Street, Building 20, 4th floors \\ Bandung, Indonesia-40135 \\ Phone: $+62-22-2504660$ Fax: $+62-22-2504659$ \\ taufiqqurrachman@gmail.com,mashury.wahab@gmail.com
}

\begin{abstract}
In this paper, design and implementation of dual band 2-Way Wilkinson Power Divider (WPD) is presented. This WPD can used for frequency of $456 \mathrm{MHz}$ (X-Band Radar) and frequency $600 \mathrm{MHz}$ (S-Band Radar). The Dual Band WPD used a two-section broadband method which consists only of cascaded sections of branch-lines $\left(\mathrm{Z}_{\mathrm{A}}\right.$ and $\left.\mathrm{Z}_{\mathrm{B}}\right)$ and Resistors $\left(\mathrm{R}_{1}\right.$ and $R_{2}$ ). The Dual Band WPD was implemented on a FR4 Substrate with $\varepsilon r=4.6$ and thickness of $1.575 \mathrm{~mm}$. From the simulation results, a good agreement about return loss, insertion loss and isolation were obtained. But in the measurement results, the WPD behaves like a wideband power divider. The simulation and measurement results show that the dual band design with the two-section broadband method is not suitable for dual band design with narrow bandwidth (about $144 \mathrm{MHz}$ ).
\end{abstract}

Keyword- Dual Band, Wilkinson Power Dividers, Two Section Broadband.

\section{INTRODUCTION}

Power Divider is one of microwave passive components that is often used in communication system and radar system. In our radar system, power divider usually used for dividing power on Dielectric Resonator Oscillator (DRO) for generate several local oscillator. The ongoing development of Radar system works on two different frequency bands, namely X-Band and S-Bands. In the X-Band radar, we use the intermediate frequency at $456 \mathrm{MHz}$, while for the SBand radar the intermediate frequency is $600 \mathrm{MHz}$. Therefore, for our radar system, a power divider that can operate on both of the Intermediate Frequency (IF) is needed.

In the past years, there are a lot of researches about dualband power divider using various methods [1] - [4]. Analysis and design of a dual band Wilkinson Power Divider (WPD) for wireless application where operated at GSM band (925-960 MHz) and (1930-1960 MHz) using Tshaped sections structure has been presented in [1]. This divider can be only, practically, designed with a high frequency ratio; on the range of 2.5 to 5.5. The Dual band WPD with -shaped sections structure has been designed in [2]. For practical realization of microstrip lines using shaped sections, the characteristic impedance should be bounded in the region $(30 \leq Z \leq 150$., so the corresponding practical frequency ratio must be in the range $(1.85 \leq R \leq 5)$.

The dual band WPD in [3] has a new configuration which consists of two-sections coupled-line and two isolation resistors. The advantage of using this method is a more convenient placements of isolation resistor since all the lines are coupled. Thus, the size of practical layout can be very small. From the theoretical analysis, this method on this divider could be used over a wide range of frequency ratios (from 1 to 3) with line impedance ranging from 60 to 85 Further works on this WPD, dual band WPD using branchlines and resistor has been designed and realized in [4] where operated at 1 and $2.5 \mathrm{GHz}$.

In this paper, the design and implementation of dual band WPD using branch-lines and resistor for intermediate frequency $(456 \mathrm{MHz}$ and $600 \mathrm{MHz})$ is presented for supporting microwave components in our radar system.

\section{DESIGN AND METHODOLOGY}

Figure 1 shows the dual band WPD configuration. This is a two-way symmetry power divider using two-section broadband which consists only of cascaded sections of branch-lines $\left(\mathrm{Z}_{\mathrm{A}}\right.$ and $\left.\mathrm{Z}_{\mathrm{B}}\right)$ and resistors $\left(\mathrm{R}_{1}\right.$ and $\left.\mathrm{R}_{2}\right)$. The characteristic impedance $\left(Z_{A}\right.$ and $\left.Z_{B}\right)$ and resistors $\left(R_{1}\right.$ and $R_{2}$ ) can be calculated using the below equation [4]:

$$
\begin{aligned}
& Z_{A}=\sqrt{\frac{n}{k}} \mathrm{Z}_{\mathrm{o}} \\
& Z_{B}=\sqrt{n k} Z_{o} \\
& R_{1}=\frac{2 Z_{o}}{1+k} \sqrt{\frac{(n-1) k}{1-k}} \\
& R_{2}=\frac{2 Z_{0}}{1-\sqrt{\frac{1-k}{(n-1 / k}}} \\
& k=\frac{(n-1) \tan ^{2} \epsilon+\sqrt{(\mathrm{n}-1)^{2} \tan ^{4} \epsilon+4 \mathrm{n}}}{2 \mathrm{n}}(5)
\end{aligned}
$$




$$
\begin{aligned}
& \epsilon=\frac{\pi}{2} \cdot \frac{f_{2} / f_{1}-1}{f_{2} / f_{1}+1} \\
& n=\frac{2 Z_{S}}{Z_{L}}
\end{aligned}
$$

In our design, we are using input impedance $\left(Z_{S}\right)$ and output impedance $\left(Z_{L}\right)$ about $50 \mathrm{ohm}$. From equation (1) - (7), values of the characteristic impedance $\left(Z_{A}\right.$ and $\left.Z_{B}\right)$ and resistor isolations $\left(\mathrm{R}_{1}\right.$ and $\left.\mathrm{R}_{2}\right)$ were found to be 82.7 , $60.43,95.11 .254 .87$.

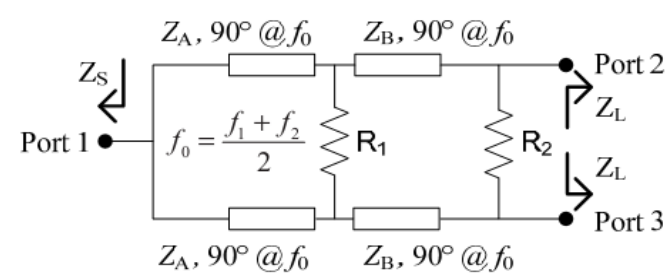

Figure 1. Configuration of dual-band WPD

\section{Simulation AND MEASUREMENT Results}

The proposed design of dual-band configuration was simulated using MoM simulation on ADS2011.10 software. Layout diagram of the proposed design optimization was carried out by changing the length of the two-section branch-lines as shown in the Figure 2. This layout was designed on FR4 substrate with a thickness of $1.575 \mathrm{~mm}$ and permittivity of 4.6. For reducing physical size of the proposed design, the two-section branch-lines was folded into a meander-coupled line so total dimension become $5.8 \times 3.9$ (in $\mathrm{mm}$ ).

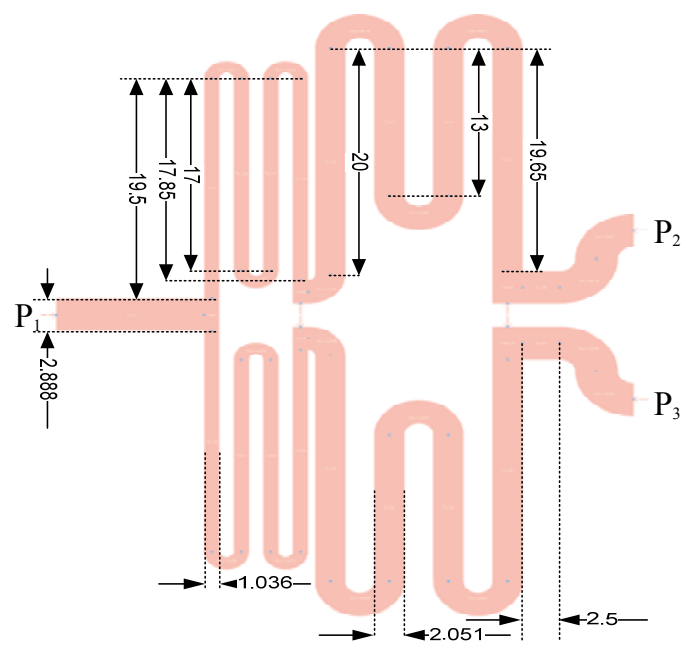

Figure 2. Layout diagram of dual-band WPD
Simulation result of the proposed design was presented on the graphs of return loss, insertion loss and isolation as shown in the Figure 3. From the graph of return loss in the Figure 3, the proposed design shows good results in every port at $456 \mathrm{MHz}$ and $600 \mathrm{MHz}$ frequencies, where the input port (denoted in S11) only returns the power of $0.095 \%$ (or VSWR of 1,064 ) at a frequency of $456 \mathrm{MHz}$ and $0.044 \%$ (or VSWR of 1,043) at a frequency $600 \mathrm{MHz}$. While the output port (denoted in the S22 and S33) only returns the power of $0.0037 \%$ (or VSWR of 1.0122 ) at a frequency of $456 \mathrm{MHz}$ and $0.0077 \%$ (or VSWR of 1,018) at a frequency of 600 $\mathrm{MHz}$. This indicates that more output port matching when compared to the input port in both frequencies.

In addition, the insertion loss of the proposed design shows nearly ideal results where the value of insertion loss at both frequencies is about $-3.03 \mathrm{~dB}$. This shows that the proposed design are proportional with the loss of about $0.2 \%$ in each output port. Isolation of the proposed design achieves good results which is about less than $-30 \mathrm{~dB}$ at both frequencies. This suggests that between the two output ports can only be bypassed by electrical signals by $0.1 \%$.

From the overall simulation results in the Figure 3, the proposed design provides a good performance at $456 \mathrm{MHz}$ and $600 \mathrm{MHz}$ frequencies which was indicated by the presence of two valleys at both frequencies on a graph of return loss and isolation.

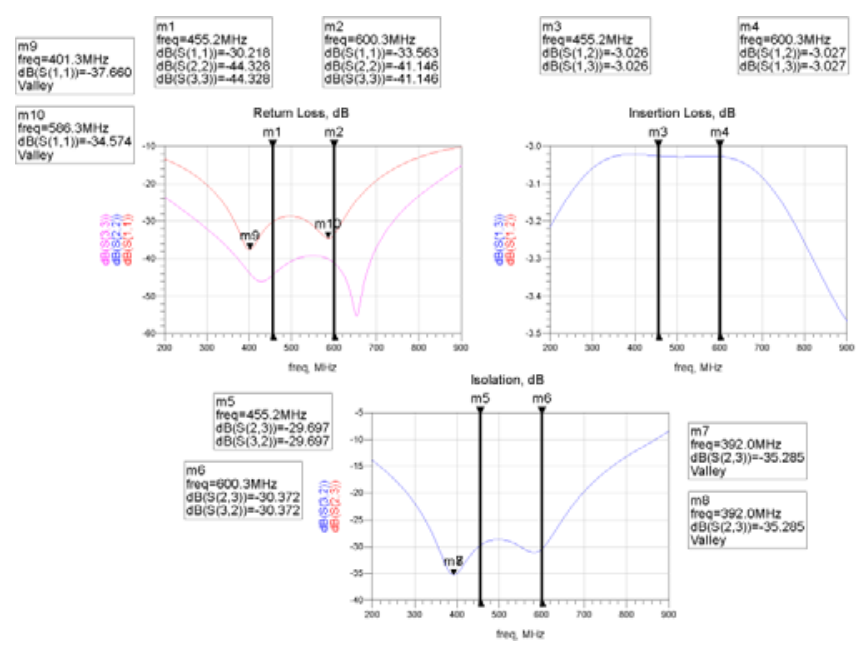

Figure 3. Simulation results of dual-band WPD.

A photograph of the proposed design that was fabricated on FR4 Substrate with thickness of $1.575 \mathrm{~mm}$ and permittivity of 4.6 , which consists of two-section branchline, two SMD resistors as isolator and SMA connectors at each input and output ports, is depicted on the Figure 4. 


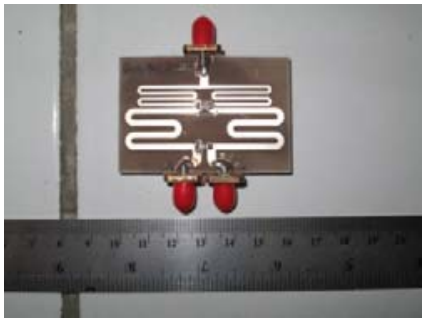

Figure 4. Photograph of fabrication dual-band WPD.

Measurement results of VSWR, insertion loss and isolation (as in the graphs of simulation results) of the proposed design using a Vector Network Analyzer (VNA) Advantest R3770 is presented in the Figures 5 to 7.

Based on VSWR graph of the Figure 5, the proposed design obtained the value around 1.1-1.2 VSWR at 456 $\mathrm{MHz}$ frequency at each port, while for the $600 \mathrm{MHz}$ frequency, VSWR values are around 1.01-1.2. This indicates that all ports on the proposed design have good impedance matching so that they will only reflect power around 0.0025 $-0.9801 \%$ on the both frequencies.

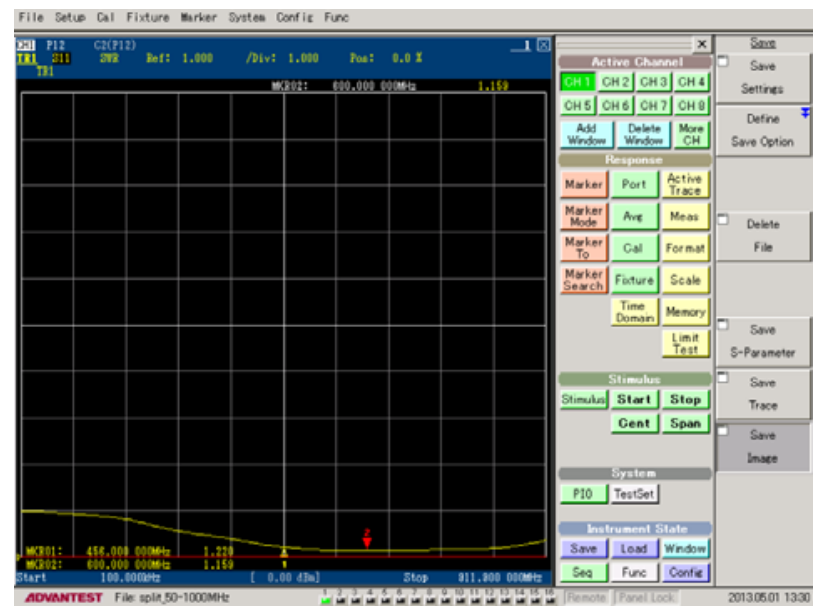

(a)

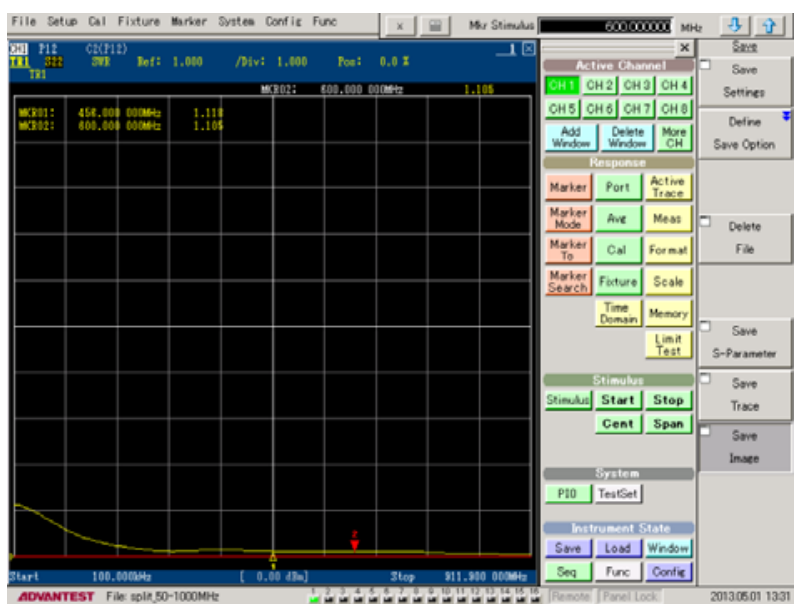

(b)

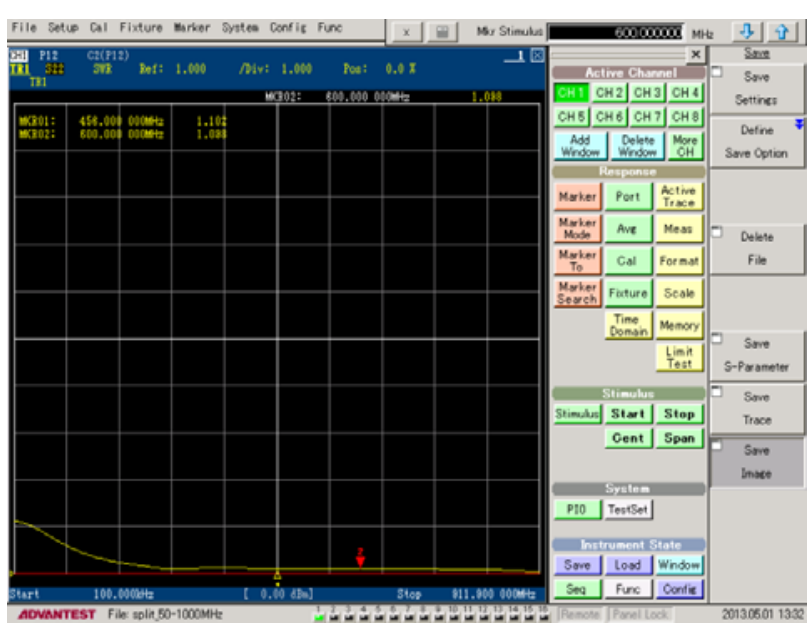

(c)

Figure 5. Measurement results of VSWR.
(a). S11
(b). S22
(c). S33

The measurement results of insertion loss of the proposed design are presented in the Figure 6 . At $456 \mathrm{MHz}$ frequency, insertion loss from port 1 to port 2 (denoted in the S12) is equal to $-3.352 \mathrm{~dB}$ (or power loss of $3.78 \%$ ) and the insertion loss from port 1 to port 3 (denoted in the S13) is equal to $-3.332 \mathrm{~dB}$ (or power loss of only $3.57 \%$ ). While on the $600 \mathrm{MHz}$ frequency, insertion loss S12 is equal to $3.394 \mathrm{~dB}$ (or power loss of only $4.23 \%$ ) and the insertion loss $\mathrm{S} 13$ is equal to $-3.364 \mathrm{~dB}$ (or power loss of only $3.91 \%$ ).

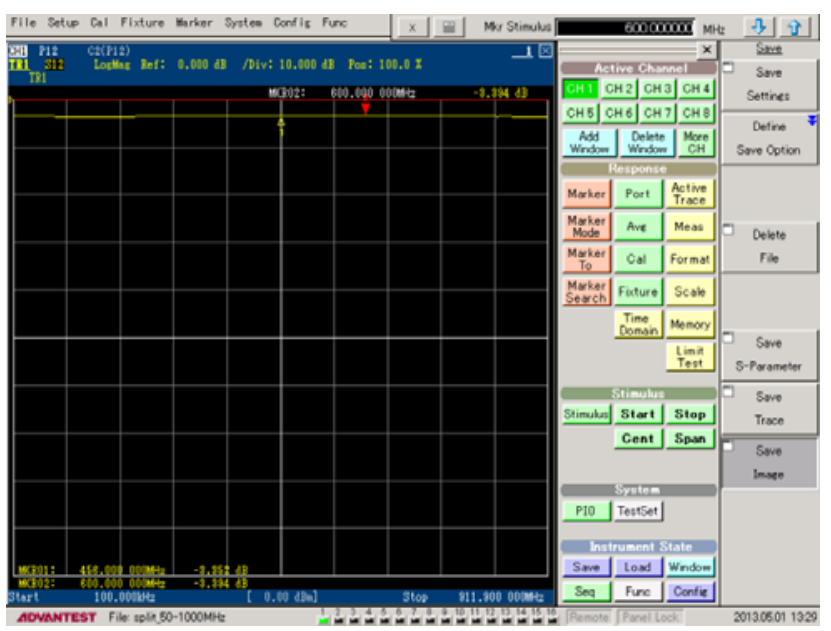

(a) 


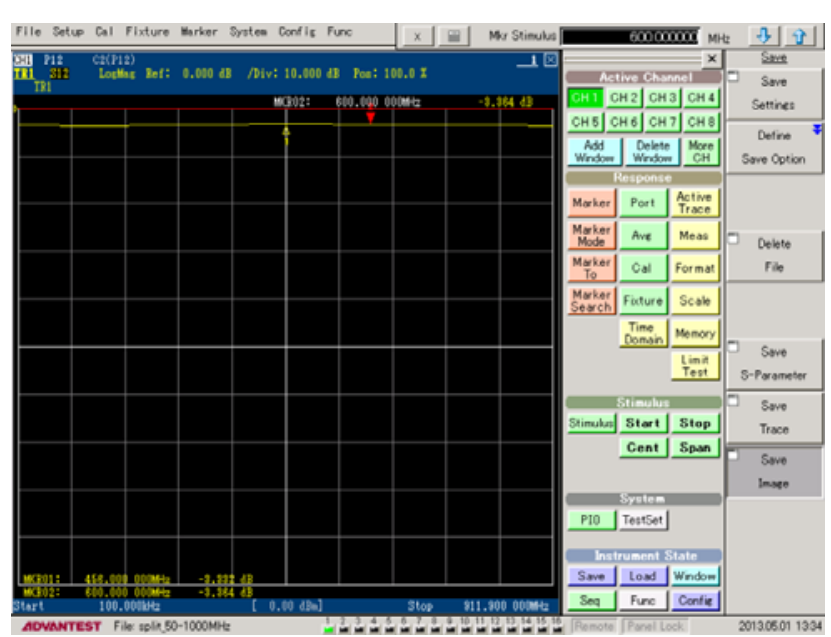

(b)

Figure 6. Measurement results of Insertion Loss
(a). S12
(b). $\mathrm{S} 13$

In the Figure 7, the measurement results of the isolation on the proposed design are shown. Isolation value of the proposed design is good enough that the value is $-22.174 \mathrm{~dB}$ (at the frequency of $456 \mathrm{MHz}$ ) and equal-19.158dB (at the frequency of $600 \mathrm{MHz}$ ). This suggests that between the two output ports of the proposed design can only pass signal by $0.61 \%$ (at a frequency of $456 \mathrm{MHz}$ ) and $1.2 \%$ (at a frequency of $600 \mathrm{MHz})$.

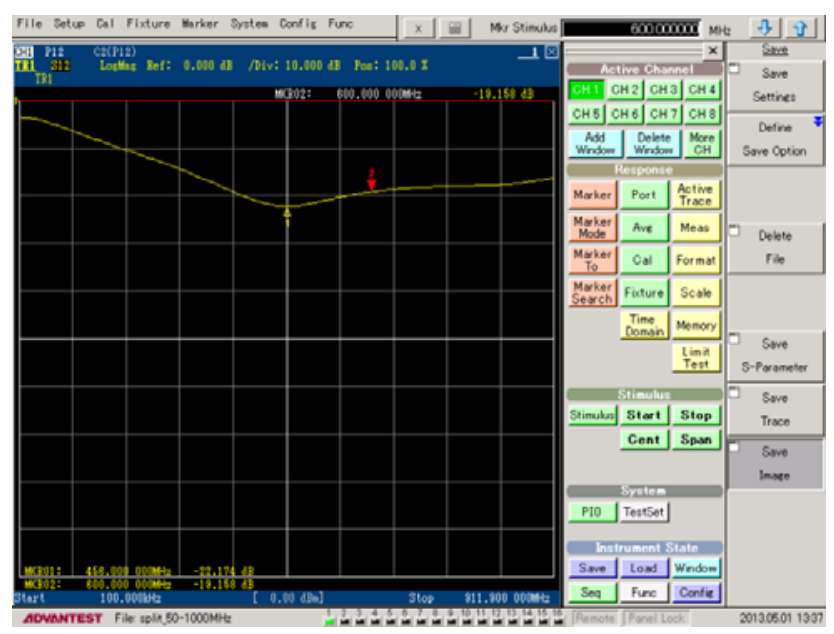

Figure 7. Measurement results of Isolation at S23.

The comparison between the simulation results and the measurement results show a similarity with a minor difference. In the graph of insertion loss, there are differences between the results of measurements and simulation of $0.3 \mathrm{~dB}$. This can occur due to imperfections in the fabrication process PCB and soldering processes. While the measurement results of the return loss/VSWR show a minor discrepancy compared with the simulation results, where on the graph, the simulation results are found to have two valleys on both the desired frequencies. This is due to the bandwidth of the proposed design is very narrow (or around $144 \mathrm{MHz}$ ) so that the measurement results will be like a wideband power splitter.

\section{CONCLUSION}

2-Way Power Divider with dual band at $456 \mathrm{MHz}$ and $600 \mathrm{MHz}$ frequency using two-section branch-lines and resistors only was designed, fabricated and measured. From the previous researches, this method can be used over a wide range of frequency ratios (from 1 to 3 ) with line impedance ranging from 60 to 85 . The good agreement between simulated and measured results (return loss/VSWR, isolation and insertion loss) was experimentally demonstrated. In our case where the bandwidth on our design is approximately $144 \mathrm{MHz}$, this method is not suitable because the measurement results shows the results behave like a wideband power divider.

\section{ACKNOWLEDGEMENT}

This project was supported by RADAR project on Research Center for Electronics and Telecommunication Indonesian Institute of Sciences (PPET-LIPI). The Authors would like to thank for my colleagues in which joining the radar research team on the PPET-LIPI.

\section{REFERENCES}

[1] Ashraf S. Mohra, Majeed A. Alkanhal, "Dual Band Wilkinson Power Dividers Using T-Sections", Journal of Microwaves, Optoelectronics and Electromagnetic Applications, Vol. 7, No. 2, pp 83-90, December 2008.

[2] Ashraf S. Mohra, "Compact Dual Band Wilkinson Power Divider", Microwave and Optical Technology Letters, Vol. 50, No. 6, pp 16781682, June 2008

[3] Yongle Wu, Yuanan Liu, Quan Xue, "An Analytical Approach for a Novel Coupled-Line Dual-Band Wilkinson Power Divider", IEEE Transactions on Microwave Theory and Techniques, Vol. 59, No. 2, pp 286-294, February 2011

[4] Carlos Law, K. K. Michael Cheng, "Compact Dual-Band Power Divider Design using Branch-lines and Resistors Only", Asia Pacific Microwave Conference 2008, pp 1-4, December 2008. 